\title{
Student-Centered Learning at Sultan Qaboos University: EFL Students' Perceptions
}

\author{
Salma Al- Humaidi ${ }^{1, *}$ \\ ${ }^{1}$ College of Education, Curriculum \& Instruction Department, Sultan Qaboos University, P.O. \\ Box 32, P.C. 123, Al-Khoudh, Oman \\ *Correspondence: Tel: 968-9727-8572 E-mail: salmahumaidi@gmail.com
}

Received: June 21, 2015 Accepted: August 3, 2015 Published: September 30, 2015

doi:10.5296/ije.v7i3.8403 URL: http://dx.doi.org/10.5296/ije.v7i3.8403

\begin{abstract}
On-going research in education is focusing on exploring various approaches driven by a growing concern of ideal teaching and learning methods. Student-Centered Learning is characterized by innovative methods of teaching and it has been promoted to support the rapidly changing education environment. This study aims at investigating EFL students' perceptions of practicing SCL in the teaching/learning process at Sultan Qaboos University. Data was gathered through a survey from 57 EFL students studying at SQU. Results show that the different dimensions of Student-Centered Learning are used to significantly varying degrees. Some implications and recommendations were elaborated in this paper.
\end{abstract}

Keywords: student-centered learning, EFL students, perceptions, Sultan Qaboos University 


\section{Introduction and literature review}

Students of the $21^{\text {st }}$ century are expected to have life and career skills, learning and innovation and information and communication technology skills. Consequently, the unwavering responsibility of educators is to ensure that these skills are promoted especially in higher education institutions. Teaching and learning methods, approaches and techniques are constantly evolving to meet these needs. Student-Centred Learning (henceforth SCL) has been promoted to support the rapidly changing education environment (Training Module Series, 2012).

SCL is characterized by innovative methods of teaching which aim to promote learning and take students as active participants for their own learning by fostering transferable skills such as problem solving, critical thinking and reflective thinking. SCL is based on: active learning and ongoing reflection, cooperation between students and instructors, higher-order thinking skills, students' choices and control over their learning, students' different experiences and background knowledge, and students' diversity. Examples of teaching methods in SCL are: lecture with discussion, class discussion, online discussion, case studies, discovery learning, learning centers, simulations and role-plays. Students' projects in SCL may include writing papers, essays and reports, individual and group projects, conducting research, answering open-ended questions and organizing events. There are differences between SCL and Teacher-Centered Learning (TCL). The following continuum lists some characteristics of both of them (Training Module Series, 2012).

\section{Student-centred Learning}

Students have choices and control over their learning.

Students are active.

Power is primarily with the student.

Assumes students have different experiences and background knowledge Students discuss the course objectives with the lecturer.

The teacher encourages students to restructure existing knowledge.

The teacher considers both summative and formative assessment (e.g. authentic tasks during the course).

Students generate their own notes.

Students discuss their changing understanding of the subject.

Instructors question students' ideas.

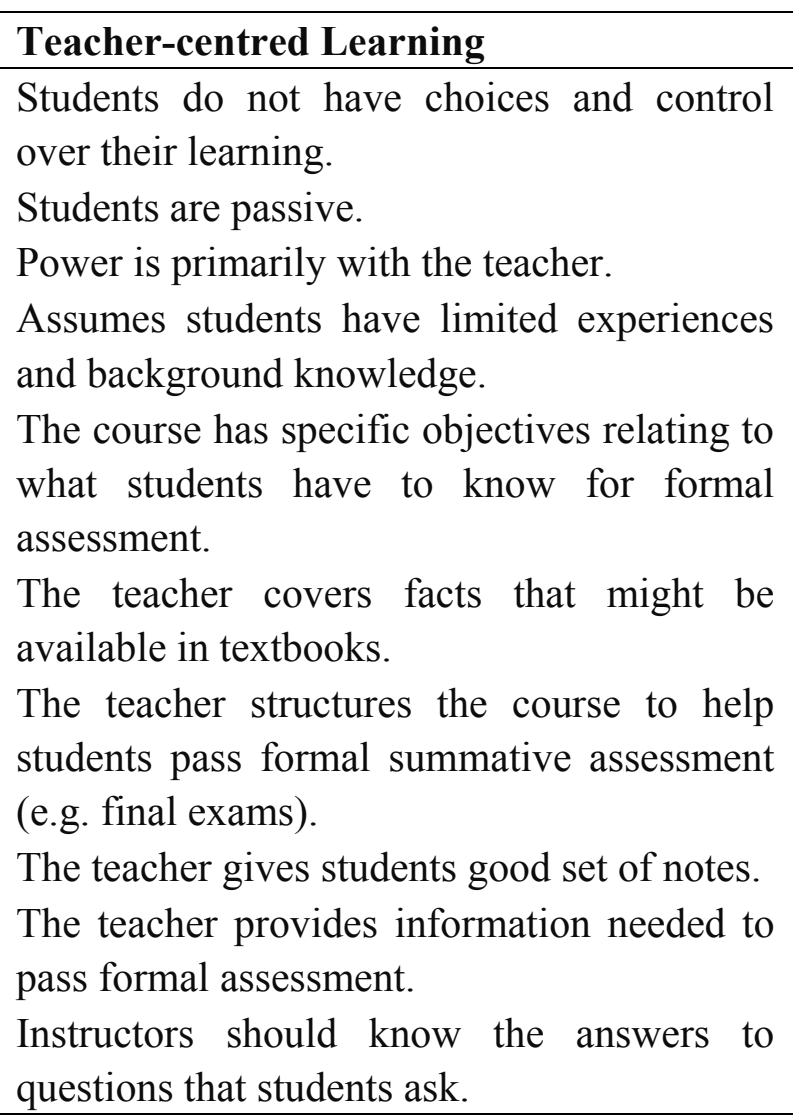




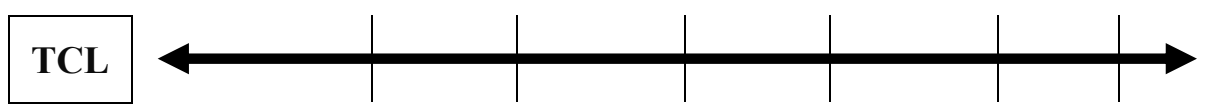

Source: Training Module Series, 2012

The main role of the teacher in SCL is to facilitate students' learning by providing activities for students to work on. At a university level, usually SCL activities are followed at different degrees in different academic programs. However, it may not be utilized systematically.

Weimer (2002) and Harris and Cullen (cited in "Student-Centred Learning: Advisory Committee Report, 2011) state five main principles that an institution needs to maintain in order for the instructors to work within the SCL paradigm and these are:

- Balance of power: creating community through sharing power and control.

- Function of content: creating relevance by focusing on what the learner learns as opposed to what the knowledge is to be disseminated.

- Role of the teacher: leaders assuming roles akin to the learner-centered teacher who is described as a facilitator, designer, or guide.

- Responsibility for learning: fostering a climate for learning by creating community.

- Assessment and evaluation: using assessment to monitor ongoing learning and gauge effectiveness (see also Wright, 2011).

Research has shown that there are different factors that determine the effective implementation of SCL Escotet, 1995; O'Sullivan, 2003; Schuh, 2004; De Guzman, 2004; Phungphol, 2005; Gravoso and Pasa 2008; Sablonniere, Taylor \& Sadykova, 2009; Sivan, Leung Woon and Kember, 2000; Thanh, 2010; Ahmed and Mahmood, 2010; Altinyelken, 2010 (a, b, c); Marlies, Kyndt, Struyven and Dochy, 2010; Alavinia, 2013; Schweisfurth, 2011; Schweisfurth, 2013; and Jabbour, 2013). As teachers play a vital role to pass the knowledge, values and skills to students, a number of studies focused on investigating teacher-related factors among which are teachers' perceptions. Research has shown that there are contextual factors that may hinder teachers from implementing student-centenred approaches (Jabbour, 2013, and Kavanoz, 2006). However, research also shows that there are inconsistencies between teachers' perceptions and their actual practices. Lee (2009), for example, found that although many teachers had a heightened awareness of the importance of using student-centred approaches, their teaching was still directed by textbooks. Wang (2007) investigated primary EFL teachers' perceptions and practices as related to student-centered learning ideology in China. He found out that although Chinese teachers overwhelmingly welcomed the new ideology of SCL for curriculum change, pedagogically, they preferred a middle path and that is the teacher-directed learner- centered approach which incorporates both learner-centered and teacher-centered teaching. 
Parallel to this line of research, collecting data from students on their teachers teaching provides meaningful data on what their teacher does (Ampadu, 2012 and Ahmed and Aziz, 2009). Ampadu, 2012, argued that "the current system of assessing teachers by examining their own perceptions of their teaching is neither reliable nor valid since it most often considers students' views as unimportant although students are directly affected by the teacher's actions and inactions" (p. 353). Furthermore, like many higher education institutions, Sultan Qaboos University (hereafter, SQU) highly recommends students' rating of their instructors.

\section{Context of the Problem}

Traditionally, teaching the courses in the teacher education programs at SQU depends on lectures, readings, presentations doing term papers, etc. Some of the faculty members adopt a task-based approach. Others are teaching about the learner-centered approach: its techniques, principles, and its applications in schools. However, it was rarely utilized systematically in classes. In 2009, SQU in Oman implemented a project for adopting SCL (in this paper also called learner-centered methodology or learner-centered approach) in the preparation program of the teacher-trainees of English at the College of Education. This project was incorporated in English Language Teaching Methods 2 course. The learning materials package used in the project was developed as a result of the collaboration of three parties: Sultan Qaboos University, the Omani Ministry of Education and the US government's Middle East Partnership Initiative (MEPI) represented by Seward Incorporated. In the package, two independent variables have been manipulated: (1) the principles of the learner-centered approach and the e-learning Moodle platform (Al-Humaidi, Al-Barwani, and Al-Mekhlafi, 2014).

Preliminary indicators and views of the participants (faculty and students) showed that the project is effective and successful for more than one reason: (1) involving students in active learning processes and tasks; (2) minimizing the use of lectures as the principle mode of instruction, (3) giving students increased ownership of their learning, (4) fostering team work and cooperative learning, and (5) manipulating technology and e-learning efficiently. Numerating these benefits, however, does not mean the absence of problems to do with assessment, quantity of the readings and assignments, use of technology, and the nature of the tasks accompanying the topics (for more details see (Al-Humaidi, 2014).

Although this project was discontinued, some instructors benefited from this experience and continued to incorporate this methodology in other courses such as English Language Teaching Methods 2. More than 6 years passed now since that project was initiated. There is a need, therefore, to continue efforts and research to achieve more understanding of this approach and shed light on the best ways to implement it more effectively. The aim of this study is to help solicit baseline data in terms of practicing SCL in SQU teaching process. The data will be used to fulfill various parameters to bridge the gap between the current SCL level in SQU with the optimal one. 


\section{Method}

\subsection{Purpose of the study}

The present study is an exploratory piece of research. It aims at exploring the implementation of SCL as perceived by EFL students. It specifically investigated the extent to which SCL is implemented and if there are significant differences in implementing the different dimensions of SCL.

\subsection{The main research questions are:}

1. To what extent is SCL implemented at Sultan Qaboos University as perceived by EFL students?

2. Are there significant differences in implementing SCL across the different dimensions as perceived by EFL students?

\subsection{Population and sample}

The population of the study consists of all students in the English language teaching (ELT) program at the College of Education at SQU with the exclusion of first year students. The study involves 47 students which comprises $20 \%$ of the population. Most of the participants are female enrolled in their third and forth ELT bachelor degree. The first year students were excluded because of insufficient experience in the program. At the time of administering the questionnaire, they had finished one semester only.

\subsection{Research instrument: Questionnaire}

The study aimed at investigating SCL implementation at SQU as perceived by EFL students. A questionnaire, aimed to collect quantitative data, was divided into three main parts. The first part asked participants for demographic information such as the degree they are enrolled in, college/department, cohort, current year of study and gender. The second and third parts were divided into different dimensions according to the specific issues of SCL being investigated. The design of the questionnaire followed a Likert-scale format of two types (extent of agreement and extent of frequency). Extent of agreement format as reflected in the question "To what extent do your instructors use/not use the following?" was used for the first six dimensions (as arranged in the questionnaire) which are: teaching methods and strategies, Goals and objectives, students' involvement in educational process, assessment, teachers' roles, and students' roles. Extent of agreement format conveyed in the question "To what extent do you agree/disagree with the following statements?", was used for the last two dimensions which are: learning outcomes and learning environment which asked the participants for their own perceptions about SCL.

\subsection{Validity and reliability of the questionnaire}

The questionnaire was validated by a panel of eight experts; six from College of Education, Curriculum and Instruction Department and two from College of Arts. The panel was requested to read the instrument and check it in terms of clarity and relevance to the purpose of the study. In the light of their suggestions and comments, the instrument was reviewed and 
modified. After establishing validity for the English version of the questionnaire, it was translated into Arabic in order to avoid any misunderstanding by the students whom Arabic is their first language. The Arabic and the English version of the questionnaire was later checked by the same panel for validity. The final version, therefore, was administered in both English and Arabic.

As for the reliability, the questionnaire was pilot tested with a group of 28 students to refine it. The Cronbach Coefficient was calculated and it was (.92). The process of questionnaire administration took place mid of Mach until first week of April, 2015. The researcher contacted the different instructors in the college of Education for their permission ant time arrangement to administer the questionnaire during class time. The researcher herself administered the questionnaires and collected them from the students.

\section{Results}

Analyses focused on identifying the most and least commonly used SCL activities in the teaching/learning process at SQU. Descriptive statistics (means and standard deviations) were first obtained for the different dimensions in general and then for the specific items under each dimension. Data obtained from the participants' responses to the questionnaire were tabulated and analyzed using Software Package for the Social Sciences (SPSS). The means and standard deviations were calculated to identify the students' perceptions of SCL implementation at SQU.

This section will answer the two research questions "To what extent is SCL implemented in SQU as perceived by EFL students?" and "Are there significant differences in implementing SCL across the different dimensions as perceived by EFL students?

The study findings about the students' perceptions regarding SCL will be presented through reporting the questionnaire results of the second and third sections. The general eight dimensions will be presented first according to the mean values from high to low. For the purpose of interpreting the data, the following scale was suggested. The advantage of this scale is that it keeps the original Likert scale and also reflects the continuous nature of the construct being considered. The means, therefore, were divided as follows:

\begin{tabular}{lllll}
\hline very high & High & Moderate & Low & very low \\
\hline $4.20-500$ & $3.40-4.19$ & $2.60-3.39$ & $1.80-2.59$ & $1.00-1.79$ \\
\hline
\end{tabular}

The following table shows the overall means and standard deviations of the eight dimensions according to questionnaire results. The grand means and standard deviations were calculated and summarized in table 1. 
Table 1. The overall means and standard deviations of the eight dimensions of SCL

\begin{tabular}{llll}
\hline No. & Dimension & Mean & Std. Deviation \\
\hline 1 & Learning outcomes & 3.78 & .64 \\
2 & Students' roles & 3.75 & .51 \\
3 & Learning environment & 3.58 & .58 \\
4 & Goals and objective & 3.29 & .57 \\
5 & Teachers' roles & 3.24 & .56 \\
6 & Teaching methods and strategies & 3.21 & .39 \\
7 & Assessment & 3.18 & .59 \\
8 & Students' involvement in educational process & 2.33 & .72 \\
\hline
\end{tabular}

The eight dimensions are ordered from highest to lowest in table 1 above based on the mean values results. Based on this table and the proposed scale for interpreting the data (above), the results reveal three main categories of mean values; high, moderate, and low, with the exclusion of very high and very low mean value ranges. Learning outcomes, students' roles, and learning environment received high mean values $(3.78,3.75$, and 3.58 respectively. Goals and objectives, teachers' roles, teaching methods and strategies, and assessment received moderate mean values $(3.29,3.24,3.21$, and 3.18). One dimension, students' involvement in educational process received a low mean value (2.33). This result indicates that SCL is generally implemented more often as reflected in the first three dimensions than the rest of the dimensions.

To answer the question "Are there significant differences in implementing SCL across the different dimensions as perceived by EFL students?

Using Wilks' Lambda analysis shows that there are significant differences in implementing the different dimensions of SCL, $\mathrm{F}(7.50)=28.04, \mathrm{p}=.00$. The test of within-subject effects was also significant, F (7.392) $=50.8$,P.00, Partial Eta Squared .48. This means that the different dimensions of SCL are implemented to significantly varying degrees. The following graph provides more clarification. In this graph, the numbers from 1-8 represent the different dimensions as ordered in the questionnaire as follow:

1. Teaching methods and strategies,

2. Goals and objectives,

3. Students' involvement in educational process,

4. Assessment,

5. Teachers' roles,

6. Students' roles,

7. Learning outcomes, and

8. Learning environment 


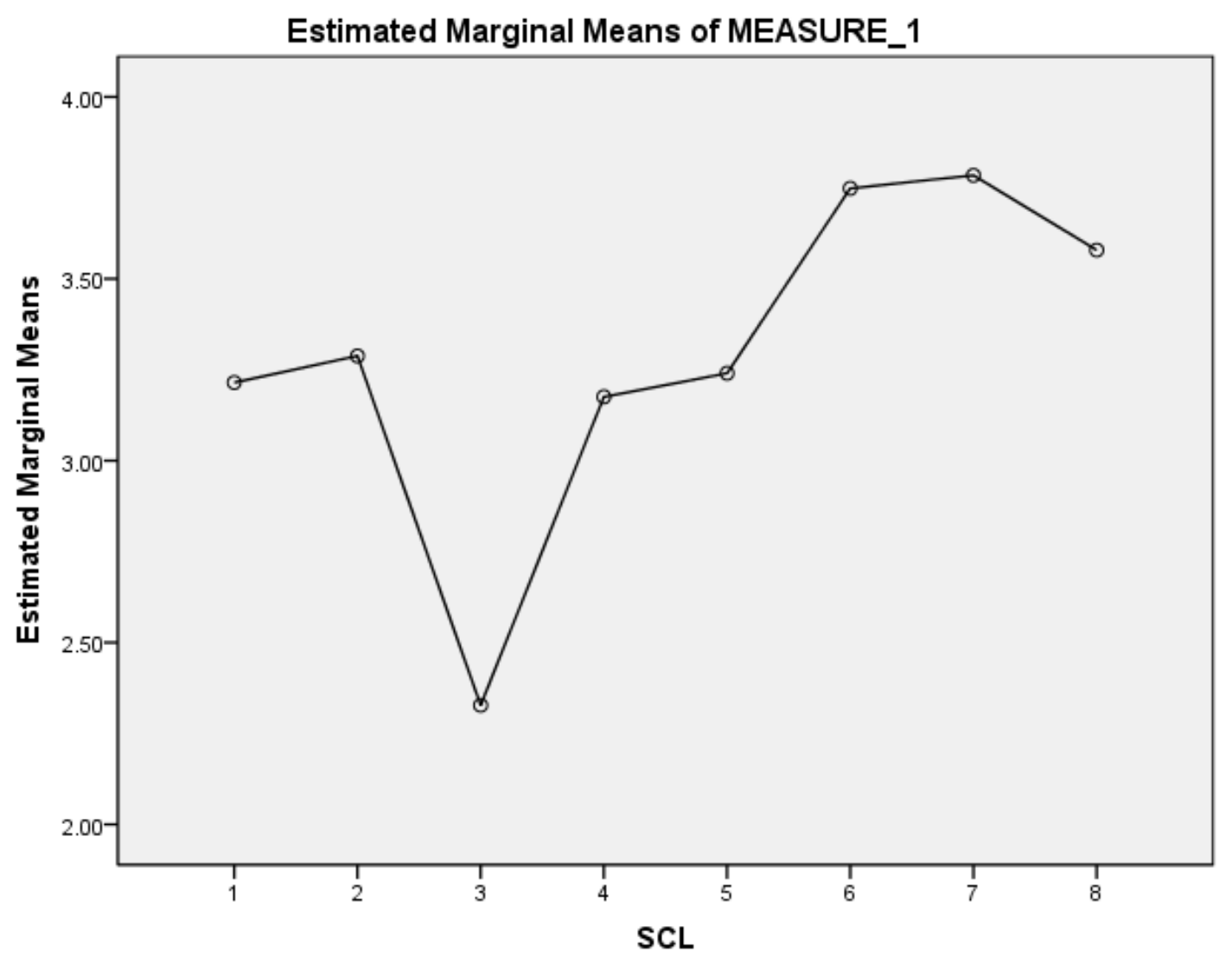

Next, the eight dimensions will be presented in the same order they were organized in the questionnaire. Then the results will be presented and discussed (se appendix 1 for the detailed results of the different items).

All of the items received high, moderate, and low mean values with none receiving very high and very low values, which is the same result for the general dimensions of SCL discussed above. The 14 items under "teaching methods and strategies" received high, moderate, and low mean values. The items lecture, lecture with discussion, cooperative learning, class discussion, self-learning, presentations, and problem-based learning received high means ranging from 4.11-3.46. This indicates that these teaching methods and strategies are implemented in the classroom frequently more often at SQU. Case-studies, discovery learning, scaffolding, and KWL: know-what to know-learned, on the other hand, received moderate mean values ranging from 3.23 to 2.88 indicating moderate or average usage of these methods. Furthermore, 3 items received the lowest means and these are: online discussion (1.81), role-play (2.40), and simulations (2.39) indicating the least frequent use.

As related to the dimension "goals and objectives" interestingly almost all items received moderate mean values ranging from 3.12 to 3.46 . This indicates that the instructors moderately follow these types of goals in their teaching as perceived by their students. The next dimension which is "students' involvement in the educational process" revealed the 
lowest results of all dimensions. Six out of seven items in this dimension got low mean values ranging from 1.91 to 2.54 except for the first item." The goals of the learning process are agreed upon between students and my lecturers" which received a moderate mean value (3.00). This means that SQU students are not satisfactorily involved in the educational process as related to consultation on curriculum content, the teaching methods used, and evaluation methods. Furthermore, there are not enough transparent procedures in place for students to be able to give feedback on the quality of the educational process and not enough consultation in periodic program quality reviews.

As related to the seven items under assessment, the first three (assessment is an integral part in teaching, assessing students based on their ability to apply knowledge, and using projects in the assessment of students) received high mean values (3.82, 3.44, and 3.63 respectively), with "assessment based on knowledge application" got the lowest mean in this category and therefore, the closest to the next mean range level (i.e. moderate). The rest of the items received moderate mean values. It should be noted that the items that got moderate mean values are the ones more related to the use of specific and important assessment methods. These are: the use of simulation tasks, the use of real life situations, and the use of self-assessment and peer-assessment.

Regarding the teacher's roles, three items of ten received high mean values. These are: "My lectures' provide the opportunity for group work" (3.75), "My lecturers actively listen to and respect students' points of view" (3.62), and "My lecturers stimulate cooperation among students" (3.51). However, seven items received average mean values ranging from 2.88-3.33. This means that some crucial roles of SCL instructor such as providing multiple means of accessing information, acting as facilitators, challenging and motivating students, being open and empathetic, using real-life problems and case studies to structure the subject matter, and helping students to use critical thinking skills are moderately practiced at SQU as perceived by EFL students.

In parallel to this, when asked about students' roles, all items except one got high mean scores ranging from 4.02-3.49. The item "I ask my questions in the class" received average mean value (3.35). It can be said that in general some important SCL students' roles are practiced at SQU as perceived by EFL students.

The dimension "learning outcomes" specifically asks students about their perceptions of SCL. All items in this dimension received high mean values (3.88-3.63). It can be said that students have positive perceptions regarding SCL. They think that SCL helps them to be more motivated, remember and link information better, form ideas with more confidence, express their opinions, and improves their performance.

In the last dimension, students were asked about their perceptions regarding the learning environment. Items number 2 got the lowest mean values (2.53). This indicates that students do not think that they have access to appropriate research and study facilities off campus. Although in the high mean range, the item "There is genuine interaction between me and my lectures" was the closest to the moderate means range and the second lowest mean in this dimension. On the other hand, students do think that they have enough access to appropriate 
research and study facilities on campus, information technology is used in teaching/learning process, there is genuine interaction among their classmates and that their class culture is cooperative, collaborative, and supportive.

\section{Conclusion and Recommendations}

This study aimed at investigating the practicing of SCL in the teaching/learning process at SQU as perceived by EFL students. Data was gathered through a survey administered to 47 undergraduate students in the third and fourth years of the English Language Teaching program in the College of Education at SQU. Results showed that some central aspects related to SCL received low and moderate mean values. This was especially true for students' involvement in the educational process, teacher's roles, assessment, some teaching methods, and goals and objectives.

The present study showed that some crucial roles of teachers- such as providing multiple means of accessing information, acting as facilitators, challenging and motivating students, being open and empathetic, using real-life problems and case studies to structure the subject matter, and helping students to use critical thinking skills- and some teaching methods were moderately practiced at SQU. This may indicate a need for teachers to help promote the facilitation of appropriate learning experiences for students in order to implement SCL more effectively.

Similar to teacher's roles and teaching methods, assessment is another major issue in SCL that deserves more and careful attention. In the current study, some crucial aspects in assessment received moderate mean values. Some researchers confirm that there is a possibility that the assessment method may not be in line with the teaching methods. In some contexts, even when SCL is incorporated, the assessment method remains $80 \%$ examination based. (Fatima and Ahmad, 2013).

Other aspects that needed more attention and found to be implemented at moderate and low levels at SQU, are students' involvement in the educational process, and goals and objectives. This calls for more support of students' involvement in the educational process at both course and program levels. However, when specifically asked about their perceptions of some aspects related to SCL in the dimension "learning outcomes", the students reported positive perceptions. This finding contradicts the findings of Emenyeouno (2012) who investigated SCL in one of the higher education institutions in Oman and found that students had poor perceptions of SCL. Due to this contradiction, further investigation is needed to help clearly understand this issue in the Omani context.

To conclude, at a university level, student-centered teaching/learning activities are usually followed at different degrees. This study has revealed that there is some attempt to implement SCL at SQU; however, some important aspects related to SCL received moderate and low mean values. It may be that there are some contextual constraints that hinder more effective implementation of SCL (see also Schweisfurth, 2013; Altinyelken, 2010 (a, b, and c); Nonkukhetkhong, Baldouf, \& Moni, 2006; Al-Mahruoqi, 2013; and Biggs, 2003). Some 
researchers (Ahmed and Mahmood, 2010; Gravoso and Pasa, 2008; O'Sullivan, 2003) confirm that there are interplay of factors such as learners' perceptions, attitudes and their characteristics, length of time needed, the appropriate instruments to be used, how student-centered approaches are to be implemented, teacher professional capacity, available resources, and cultural factors. More studies are therefore required for better understanding of SCL at SQU. Recommendations for further research may include: 1) a replication of this study using a bigger sample and different majors in the college of education and other colleges at SQU, 2) a study that examines the perceptions of teachers about their own teaching and SCL which would help reveal interesting findings that may support or contradict students' perceptions, and 3) a study that uses various research instruments and tools, such as questionnaires, observation and other tools like document analyses to ensure more reliable findings.

\section{References}

Ahmed, Z., \& Mahmood, N. (2010) Effects of Cooperative Learning vs. Traditional Instruction on Prospective Teachers' Learning Experience and Achievement. Ankara University. Journal of Faculty of Educational Sciences, 43(1), 151-164

Ahmed, F., \& Aziz, J. (2009). Students' perception of their teachers' teaching of literature: communicating and understanding through the eyes of the audience. European Journal of Social Science, 7(3), 17-26.

Alavinia, P. (2013). Learner-Centered Education in International Perspective: Whose pedagogy for whose development? Iranian Journal of Language Teaching Research (Book Review), 1(3), 115-119.

Al-Humaidi, S. (2014). Learner-centered Methodology and Teacher Performance. International Journal of English: Literature, Langauge and Skills (IJELLS), 3(3), 197-206

Al-Humaidi, S., Al-Barwani, T., \& Al-Mekhlafi, A. (2014). Leraner -centered Instruction in Pre-Service Teacher Education. Does it make a real difference in learners' language performance? International Journal of Education (IJE), 6(4), 93-106. http://dx.doi.org/10.5296/ije.v6i4.6752

Al-Mahrouqi, N. (2013). EFL Teachers' Perceptions and Difficulties of Omani Learner-centered Approach. Master thesis. Sultan Qaboos University, Oman

Altinyelken, H. K. (2010) (b). Curriculum Change in Uganda: Teacher perspectives on the new thematic curriculum. International Journal of Educational Development, 30(2), 151-171. http://dx.doi.org/10.1016/j.ijedudev.2009.03.004

Altinyelken, H. K. (2010) (C). Pedagogical Renewal in sub-Saharan Africa: the case of Uganda. $\mathrm{PhD}$ dissertation, University of Amsterdam.

Altinyelken, H. K. (2010)(a). Pedagogical Renewal in Sub-Saharan Africa: The case of 
http://dx.doi.org/10.1080/03050061003775454

Ampadu, A. (2012). Students' Perceptions of their teachers' teaching of mathematics: The case of Ghana. International Online Journal of Educational Sciences, 4(2), 351-358.

Biggs, J. (2003). Teaching for quality learning at university. Second Edition. Buckingham, SRHE \&The Open University Press.

De Guzman, A. B. (2004). The Hermeneutics of Learner-Centered Approaches and Initiatives in the Philippines Basic Education Sector. Educational Research for Policy and Practice, 3(3), 223-241. http://dx.doi.org/10.1007/s10671-005-4311-z

Emenyeouno, O. C. (2012). Student-Centred Learning in Oman: Challenges and pitfalls. International Journal of Learning and Development, 2(5), 243-254.

Escotet, M. A. (1995). A Teacher Centered University Education: Is the core university culture different between developed and developing countries? A paper presented to the Comparative International Education Society Annual Meeting, Boston, Massachusetts, March 29-April 2, 1995.

Fatima. A. H., \& Ahmad, N. (2013). Student-Centered Learning in a passive learning environment: Students' perceptions and performance. International Journal of Economics and Management, 7(1), 84-107

Gravoso, R.S., \& Pasa, A. E. (2008). Design and Use of Instructional Materials for Student-Centered Learning: A Case in Learning Ecological Concepts. The Asia-Pacific Education Researcher, 17(1), 109-120. http://dx.doi.org/10.3860/taper.v17i1.353

Harris and Cullen (cited in "Student-Centred Learning: Advisory Committee Rgeport, 2011). Memorial University of Newfoundland Teaching and Learning Framework.

Jabbour, K. J. (2013). Issues that restrain teachers from adapting student-centered instruction in Lebanese School. Tejuelo, 17, 85-96

Kavanoz, S. H. (2006). An Exploratory study of English language teachers' beliefs, assumptions and knowledge about learner-centeredness. The Turkish Online Journal of Educational Technology (TOJET), 5(2), 3-9

Lee, J. (2009). Perceptions of ELT among English Language Teachers in China. Education Journal, 32(1-2), 137-154

Marlies B., Kyndt, E. Struyven, K., \& Dochy, F. (2010). Using Student-Centered learning environment to stimulate deep approaches to learning: Factors encouraging or discouraging their effectiveness. Educational Research Review, 5(3), 243-260. http://dx.doi.org/10.1016/j.edurev.2010.06.001

Nonkukhetkhong K., Baldouf Jr. R. B., \& Moni, K. (2006). Learner-Centerdness in Teaching English as a foreign language. Paper presented at $26^{\text {th }}$ Thai TESOL International Conference, Chiang Mai, Thailand, 19-21 January, 1-9. 
O'Sullivan, M. (2003). The reconceptualisation of learner-centred approaches: a Namibian case study. International Journal of Educational Development, 24, 585-602. http://dx.doi.org/10.1016/S0738-0593(03)00018-X

Phungphol, Y. (2005). Learner-Centered Teaching Approach: A paradigm shift in Thai education. ABAC Journal, 25(2), 5-16.

Sablonniere, R., Taylor, D., \& Sadykova, N. (2009). Challenges of applying a student-centered approach to learning in the context of education in Kyrgyzstan. (article in press). International Journal of Educational Development, 1-7.

Schuh, K. L. (2004). Learner-centered principles in teacher-centered practices? Teaching and Teacher Education, 20, 833-846. http://dx.doi.org/10.1016/j.tate.2004.09.008

Schweisfurth, M. (2011). Learner-Centered Education in developing country contexts: From solution to problem? International Journal of Educational Development, 31(2011), 425-432. http://dx.doi.org/10.1016/j.ijedudev.2011.03.005

Schweisfurth, M. (2013). Learner Centered Education in International Perspective. Journal of International and comparative Education, 2(1), 1-8.

Sivan, A., Leung, R. W., Woon, C., \& Kember, D. (2000). An Implementation of Active Learning and its Effect on the Quality of Student Learning', Innovations in Education and Teaching International, 37(4), 381-389. http://dx.doi.org/10.1080/135580000750052991

Thanh, P. (2010). Implementing a Student-Centered Learning Approach at Vietnamese Higher Education Institutions: Barriers under Layers of Casual Layered Analysis. CLA, 15(1), 21-38.

Training Module Series: Student-centered learning approaches for innovative teaching (2012). Center for Development of Academic Excellence (CDAE), University Sains Malaysia (USM).

Wang, Q. (2007). Primary EFL in China: Teachers' Perceptions and practices with regard to learner-centeredness. UK: University of Warwick Press.

Weimer, M. (2002). Learner Centered Teaching: Five key changes to practice. San Francisco CA: Jossey-Bass.

Wright, G. B. (2011). Student-Centered Learning in Higher Education. International Journal of Teaching and Learning in Higher Education, 23(3), 92-97. 


\section{Appendix 1}

Descriptive Statistics for all items in the different dimensions

\begin{tabular}{|c|c|c|}
\hline & Mean & Std. D \\
\hline \multicolumn{3}{|l|}{ Teaching Methods and strategies } \\
\hline $\begin{array}{l}\text { Lecture: the instructor gives a lecture and leaves a short time for students' } \\
\text { questions at the end. }\end{array}$ & 3.57 & 1.10 \\
\hline $\begin{array}{l}\text { Lecture-Discussion (a combination of lecture and teacher/students questioning } \\
\text { during the lecture). }\end{array}$ & 4.02 & .67 \\
\hline $\begin{array}{l}\text { Case study: a specific real-life situation or imagined scenario. Students are } \\
\text { required to analyze the prescribed cases and present their interpretations or } \\
\text { solutions, supported by the line of reasoning employed and assumptions made. }\end{array}$ & 2.98 & .86 \\
\hline Cooperative Learning (student groups working together to complete a task). & 3.79 & .75 \\
\hline Class Discussion (Students discuss in pairs/groups). & 3.63 & .84 \\
\hline Online Discussion. & 1.81 & .85 \\
\hline $\begin{array}{l}\text { Discovery Learning (an inquiry-based learning method in which learners use } \\
\text { prior knowledge and experience to discover new information that they use to } \\
\text { construct learning). }\end{array}$ & 2.88 & 1.06 \\
\hline $\begin{array}{l}\text { Self-learning (students work independently or with small groups; sometimes } \\
\text { without the presence of the teacher and by relying on different sources of } \\
\text { information). }\end{array}$ & 3.4 & 1.02 \\
\hline Role-Play (acting the role of a specific person or acting a specific situation). & 2.40 & .80 \\
\hline $\begin{array}{l}\text { Presentations (students individually or groups develop a topic and present it to } \\
\text { class). }\end{array}$ & 4.11 & .84 \\
\hline Simulations (put the student in a "real" situation or mimicking a real situation). & 2.39 & .82 \\
\hline $\begin{array}{l}\text { Scaffolding (involves the teacher modelling the skill and thinking for the } \\
\text { student. As the student understanding increases, the teacher withdraws the } \\
\text { assistance gradually allowing the student to take on more responsibility for the } \\
\text { learning). }\end{array}$ & 3.23 & 1.41 \\
\hline $\begin{array}{l}\text { KWL: Know - What to Know - Learned (a strategy that is typically used to } \\
\text { provide structure to the learning process to allow students to recall what they } \\
\text { know about a topic, what they want to know about the topic and what is to be } \\
\text { learned). }\end{array}$ & 3.11 & .92 \\
\hline Problem-based learning: (the teacher presents a problem for students to solve). & 3.51 & .77 \\
\hline \multicolumn{3}{|l|}{ Goals and Objectives } \\
\hline $\begin{array}{l}\text { The development of transversal skills by students is one of the objectives of the } \\
\text { learning process in my lecturers' teaching. }\end{array}$ & 3.26 & .84 \\
\hline $\begin{array}{l}\text { The students have high responsibility in the learning process in my lecturers' } \\
\text { teaching. }\end{array}$ & 3.46 & .95 \\
\hline
\end{tabular}




\section{NI Macrothink}

International Journal of Education

ISSN 1948-5476

2015, Vol. 7, No. 3

Peer learning and peer teaching are parts of the learning process in my lecturers' teaching.

The emphasis of my lecturers' teaching is on communicating knowledge effectively.

\section{Students' involvement in educational process}

The goals of the learning process are agreed upon between students and my lecturers.

My lecturers consult students on curriculum content.

My lecturers consult students on the teaching methods used.

My lecturers consult students on the evaluation methods used.

There are transparent procedures in place for students to be able to give feedback on the quality of the educational process.

Students are consulted in periodic program quality reviews.

\begin{tabular}{|l|l|}
\hline 1.95 & .92 \\
\hline 2.18 & 1.00 \\
\hline 1.91 & .85 \\
\hline 2.54 & 1.00 \\
\hline 2.39 & 1.28 \\
\hline
\end{tabular}

\section{Assessment}

Assessment is an integral part of learning in my lecturers' teaching practice.

My lecturers assess students based on their ability to apply knowledge.

My lecturers use projects in the assessment of the students.

My lecturers use simulation tasks in the assessment of students

My lecturers use real life situations in the assessment of the students.

My lecturers use self-assessment as a method in the student assessment.

My lecturers use peer-assessment as a method in the student assessment.

\begin{tabular}{|l|l|}
\hline 3.82 & 1.04 \\
\hline 3.44 & 1.00 \\
\hline 3.63 & .90 \\
\hline 2.70 & .76 \\
\hline 2.98 & 1.00 \\
\hline 2.84 & 1.07 \\
\hline 2.81 & 1.00 \\
\hline
\end{tabular}

\section{Teachers' roles}

My lecturers provide multiple means of accessing information.

My lecturers act as a facilitator.

My lecturers provide the opportunity for group work.

My lecturers actively listen to and respect students' points of view.

My lecturers stimulate cooperation among students.

My lecturers challenge and motivate students.

My lecturers are open and empathetic toward students.

My lecturers use real-life problems to structure the subject matter.

My lecturers use case studies to structure the subject matter.

F10. My lecturers help students to refine their understanding by using critical thinking skills.

\begin{tabular}{|l|l|l|}
\hline 3.09 & .71 \\
\hline 3.09 & .87 \\
\hline 3.75 & .69 \\
\hline 3.62 & .70 \\
\hline 3.51 & .83 \\
\hline 3.14 & .81 \\
\hline 2.88 & .99 \\
\hline 3.26 & .77 \\
\hline 2.75 & .97 \\
\hline & 3.33 & .91 \\
\hline
\end{tabular}

\section{Students' roles}

\begin{tabular}{|l|l|l|}
\hline I am active knowledge seeker. & 3.81 & .77 \\
\hline I participate in class discussion. & 3.49 & .95 \\
\hline I ask my questions in the class. & 3.35 & .99 \\
\hline I work in collaboration with my classmates. & 4.02 & .69 \\
\hline I participate in project groups to solve problems. & 3.98 & .74 \\
\hline
\end{tabular}


I construct the knowledge and meaning by interacting both with my lecturer and data gathered through different sources.

\section{Learning outcomes}

I am more motivated to learn through Student-centred learning (SCL).

I remember the information better through SCL.

I can link information better through SCL.

I form the ideas with more confidence in SCL.

I gain more self-confidence through SCL.

I can express my opinions in SCL.

SCL improves my performance.

\section{Learning environment}

I have access to appropriate research and study facilities on campus.

I have access to appropriate research and study facilities off campus.

Information technology is used within the teaching/learning process.

There is genuine interaction between me and my lecturers.

There is genuine interaction among my classmates.

My class culture is cooperative, collaborative, and supportive.

\begin{tabular}{|l|l|}
\hline 3.75 & .79 \\
\hline 3.63 & .79 \\
\hline 3.88 & .78 \\
\hline 3.72 & .77 \\
\hline 3.81 & .81 \\
\hline 3.86 & .74 \\
\hline 3.84 & .80 \\
\hline & \\
\hline 3.81 & .99 \\
\hline 2.51 & 1.26 \\
\hline 3.93 & .86 \\
\hline 3.42 & .93 \\
\hline 4.00 & .90 \\
\hline 3.81 & .95 \\
\hline
\end{tabular}

\section{Copyright Disclaimer}

Copyright for this article is retained by the author(s), with first publication rights granted to the journal.

This is an open-access article distributed under the terms and conditions of the Creative Commons Attribution license (http://creativecommons.org/licenses/by/3.0/). 